\title{
An experimental investigation into innovative pavements for city logistics
}

\author{
F. G. Praticò, A. Moro \& P. D’Agostino \\ DIIES - Dipartimento di Ingegneria dell'Informazione, delle \\ delle Infrastrutture e dell'Energia Sostenibile, \\ Università Mediterranea di Reggio Calabria, Italy
}

\begin{abstract}
Crumb rubber modified asphalt mixtures (CRM, dry process) involve the blending of crumb rubber (usually $1 \%-3 \%$ by weight of the total mixture, sizes $2.0 \mathrm{~mm} / 6.3 \mathrm{~mm}$ ) with hot aggregates prior to mixing with asphalt binder. It may cost more than conventional asphalt concretes.

On the contrary, the wet process implies incorporating crumb rubber into asphalt binder prior to mixing with aggregates (usually about $1 \%$ by weight of the total mixture, $18-25 \%$ by weight of bitumen, rubber sizes below about 0.18 $0.42 \mathrm{~mm}$ ) and has a wide and quite sound theory and procedure system behind it. Crumb rubber modified asphalt pavements may cost 1.5 to 2 times as much as conventional asphalt concrete.

Importantly, although the dry process has a number of technical issues (including lack of standards, and uncertain performance), it has the potential to recycle more crumb rubber compared with the wet process and its mechanical properties (modulus and mechanical impedance) appear to have the potential for constructing innovative urban and rural infrastructures and for greening European city terminals.

In light of the above, the goals of this study were the following: a) designing and testing innovative bituminous mixtures containing high percentages of crumb rubber (dry process); b) designing and testing innovative pavements in which the pressures caused by vehicles and/or motorcycles and/or pedestrians are converted into energy. Several mixes were designed and produced. Based on the results obtained, several options emerged as a possible solution for urban and rural roads, aiming at a better management of flow of goods and transport activities in urban areas while considering lower environmental impacts.
\end{abstract}


Although studies are in progress, results are quite encouraging and can benefit both researchers and practitioners.

Keywords: crumb rubber, dry process, urban transport, pavement, freight terminal, city logistics, urban transport centre.

\section{Introduction}

Crumb rubber (CR) can be used to modify asphalt mixtures. CR is made of tyres or vulcanized rubber from different devices and tools. For example, the components of fire extinguishers include metallic parts (discharge valve assembly, squeeze grip release lever locking pin d-yoke ring, carrying handle, band horn clip, insulated handle, and horn), but also rubber parts (hose, etc.).

Hose material is usually ethylene propylene diene monomer (EPDM) rubber. It is a type of synthetic rubber, and it is an elastomer characterized by a wide range of applications. The $M$ refers to its classification in ASTM standard D1418 , where the $\mathrm{M}$ class includes rubbers having a saturated chain of the polymethylene type.

The ethylene content is around $45 \%$ to $85 \%$. The main properties of EPDM are its heat, ozone, and weather resistance. Density can be compounded from 0.90 to more than $2 \mathrm{~g} / \mathrm{cm}^{3}$.

Tyres are basically formed by combining natural and synthetic rubber and carbon black [1].

$\mathrm{CR}$ is typically referenced by its size together with basic compositions such as natural and synthetic rubber, steel, fibre and carbon black. In tyre production, the vulcanization process plays a fundamental role and enhances its elasticity and strength properties.

There are two main methods for processing scrap tyres and other waste rubbers, namely ambient granulating (crackermill process) and cryogenic grinding [1].

Two different processing methods are usually used to combine rubber, aggregates and asphalt binder: wet and dry process.

In the wet process $[2,3]$, fine rubber is blended with hot bitumen to produce a rubberised bitumen binder. The wet process implies incorporating crumb rubber into an asphalt binder prior to mixing with aggregates (usually about $1 \%$ by weight of the total mixture, $18 \%-25 \%$ by weight of bitumen, rubber sizes below about $0.18-0.42 \mathrm{~mm}$ ) and has a wide and quite sound theory and procedure system behind. Crumb rubber modified asphalt pavements may cost 1.5 to 2 times as much as conventional asphalt concrete.

Crumb rubber modified asphalt mixtures (CRM, dry process) involve the blending of crumb rubber (usually $1 \%-3 \%$ by weight of the total mixture, sizes $2.0 \mathrm{~mm} / 6.3 \mathrm{~mm}$, see [4-6]) with hot aggregates prior to mixing with an asphalt binder. It may cost more than conventional asphalt concretes.

Usually a proportion of the mix aggregate is substituted with coarse rubber, thereby causing the rubber to function essentially as an elastic aggregate within the mixture [1]. 
In the dry process, composition (rubber gradation, rubber content, aggregate gradation, bitumen type and quantity) and process (reaction time between asphalt binder and rubber particles, etc.) affect mixture properties.

Rubber-bitumen interaction is supposed to be based on the following phenomena: rubber absorbs the maltenes fraction (which has low molecular weight) and leaves the residual bitumen containing a higher portion of asphaltenes (of high molecular weight) which increases its viscosity (see [1, 79]) and causes the increase of the dimensions of the rubber network (swelling).

By limiting the above reaction time and using a coarse granulated rubber with a low surface area, the rubber particles may be able to retain their physical shape and rigidity. The curing period seems to be necessary so as to provide sufficient time for the rubber to swell and partially dissolve in the bitumen prior to compaction [1]. Better performance can be achieved by providing a long interaction time between the rubber and bitumen but not in excess of 2 hours.

For CRM mixture performance, the main advantages and disadvantages may include (see $[1,3,10,11])$ : i) the ability to break up ice; ii) a better skid resistance during icy conditions; iii) the enhancement of elastic recovery properties under repeated loading; iv) the enhancement of the mixture's resistance against fatigue cracking; v) the improvement of crack reflection control; vi) the improvement of fatigue life; vii) the improvement of reflective cracking resistance if a minimum rubber content is added to the paving mix (probably between 1 and 2 percent by weight of aggregate); viii) the decrease of the resilient modulus; ix) the reduction of the resistance to permanent deformation; $x$ ) the reduction of Marshall stability values.

Lopez-Moro et al. [12] carried out a microscopy study of the modification of bitumen with crumb rubber, using the dry process. They observed: i) the transfer of maltenes to the rubber and carbon black to the bitumen, causing the absorption of the lighter-oil fractions of bitumen; ii) that the modification increased the stiffness of the bitumen, resulting in an improvement in the binder's resistance to rutting. Feiteira-Dias et al. [13] evaluated the mechanical response of two gap-graded asphalt rubber mixtures manufactured by the dry process and compared results; a) with that of a similar gap-graded mixture without rubber granulate; b) with analogous asphalt rubber mixes produced elsewhere by the wet process. They found that the mechanical performance of the dry mixes was better than that measured for the reference blend and was at the same level of performance as the wet mixes.

The above advantages and disadvantages might suggest the possibility to use these materials in given applications (inverted pavement structures; softer asphalt concretes with lower modulus and higher allowable strain limit and lower noise, etc., see [14-18]). Static possible applications could refer also to equipment and automobile parking (porous asphalt on low modulus hot mix asphalts (HMA)), intermodal yard (traditional HMA on low modulus HMA), gate facilities and secondary gate facilities (traditional HMA on low modulus HMA), wheeled and grounded container storage (in association with rolled cement concretes), expansion areas (traditional HMA on low modulus HMA), wharf areas (in association with rolled cement concretes), historical locations (see [19-21]). 
Another opportunity refers to the use of sensors embedded into the pavement layers in order to improve pavement management systems, safety and security in urban and rural conditions and in intermodal freight connectors.

Continuous monitoring of the pavement structural/surface condition (using self-powered sensors) with periodic high-speed inspections of the surface can enable us to optimize cost, timing and intensity of maintenance and rehabilitation treatments. For the self-powered systems for data gathering (smarter maintenance and rehabilitation), an energy harvesting stick can generate the power, with additional, advanced applications (gathering and transmission of accident, speed, weather, pollution data; energy supply for road safety systems; gathering and transmission of administrative data, etc.). The self-powered systems for data gathering have a technology concept formulated readiness level (see [22-25]).

The monitoring effect on agency, user and externality costs involves the consideration of the reliability of a pavement (probability that a pavement section designed using the process will perform satisfactorily for the anticipated traffic and environmental conditions for the design period). The following factors may impact the design reliability: materials; subgrade; traffic prediction accuracy; construction methods; and environmental uncertainties.

The following main issues still need to be addressed for smarter maintenance and rehabilitation of multimodal transportation infrastructures: i) survey-based asset management systems do not necessarily allow a timely and productive management of the infrastructure. This issue calls for further research; ii) a better amalgamation between information communication technology (ICT) and infrastructure management should be pursued. Indeed, they both can address the overall aim of smarter transport infrastructures, by affecting users' costs (information, time), agency costs (work zones, long-life), and externality costs (carbon footprint of maintenance and rehabilitation occurrences); iii) when lowvolume roads, pedestrian facilities, bicycle paths, low emission zones are taken into consideration, several energy harvesting systems, based on pressure-voltage transformation on a fixed path, may fail to achieve the best solution and other systems can achieve viable results. These issues call for further research and investigation.

The recycling of reclaimed asphalt pavement (RAP) interacts with the above issues and opportunities. Medium- to very high-content of reclaimed asphalt pavement use was reported by a number of authors [26-35].

In contrast, different strategies of blending and use of RAP (e.g., blends with recycled concrete aggregate, with rice husk ash, with lateritic soil, with asphalt shingle, use in granular bases and subbases) were proposed by others [36-41].

Importantly, based on mechanical properties and layer design (modulus, thickness, Poisson coefficient), life cycle cost analysis can be helpful in assessing the present value of each solution and then its real competitiveness [42].

Finally, it may be observed that last-mile and long distance logistics [43, 44], microsimulation in the city terminal [45], and urban regeneration aspects [46] are other relevant topics not discussed in the following. 


\section{Objectives}

Although the dry process has a number of technical issues (including lack of standards, and uncertain performance), it has the potential to recycle more crumb rubber compared to the wet process and its mechanical properties (modulus, mechanical impedance) appear to have the potential for constructing innovative urban and rural infrastructures and for greening European freight terminals.

Consequently, the following objectives were pursued: a) designing and testing innovative bituminous mixtures containing waste rubber; b) designing and testing innovative pavements in which the pressures caused by vehicles and/or motorcycles and/or pedestrians are converted into energy.

\section{Experiments and analyses}

Figure 1 summarises the overall experimental plan, in terms of crumb rubber characteristics and mixes produced. Figures 2-3 illustrate the results obtained.

Figure 2 shows how the Marshall stability (MS, kN, y-axis) varies as a function of the air voids content (AV, \%, x-axis), for crumb rubber modified asphalt mixtures (Y CR), asphalt mixtures without crumb rubber (NO CR), and all the mixtures (ALL), under the given hypotheses.

Note that: i) only two gradations were considered (type A, for dense-graded friction courses and type B, for porous asphalt concretes); ii) the same percentage of asphalt binder was considered (nominal value of $5.5 \%$ by weight of mix); iii) CRM asphalt mixtures contained the same percentage of CR $(10 \%$, which substituted the corresponding mineral aggregate portion); iv) the same type of asphalt binder was used (penetration grade: 50-70).

Figure 3 illustrates how the Marshall quotient (MQ, $\mathrm{kN} / \mathrm{mm}$ ) varies as a function of $\mathrm{AV}$, for the same mixes.

Results demonstrate that the addition of $\mathrm{CR}$ to the mixtures implies a reduction of Marshall stability and quotient. It appears noteworthy to highlight that the asphalt binder film thickness depends on particle specific gravity which changes when aggregate specific gravity changes [47-49]. Consequently, the above comparison, which entails the use of the same percentage of bitumen, appears to bring us to conclusions which are consistent with the ones reported in $[1,8]$.

As a part of the overall experimental plan (projects CADI-PIA Gomme, Cadi dei Fratelli Milasi Srl, Reggio Calabria, Italy and project SUS PAV), mixes with different percentages of bitumen and the same asphalt film thickness are under production. Similarly, experiments involving the use of reclaimed asphalt pavement, sensors and piezoelectric energy systems are currently going on. 

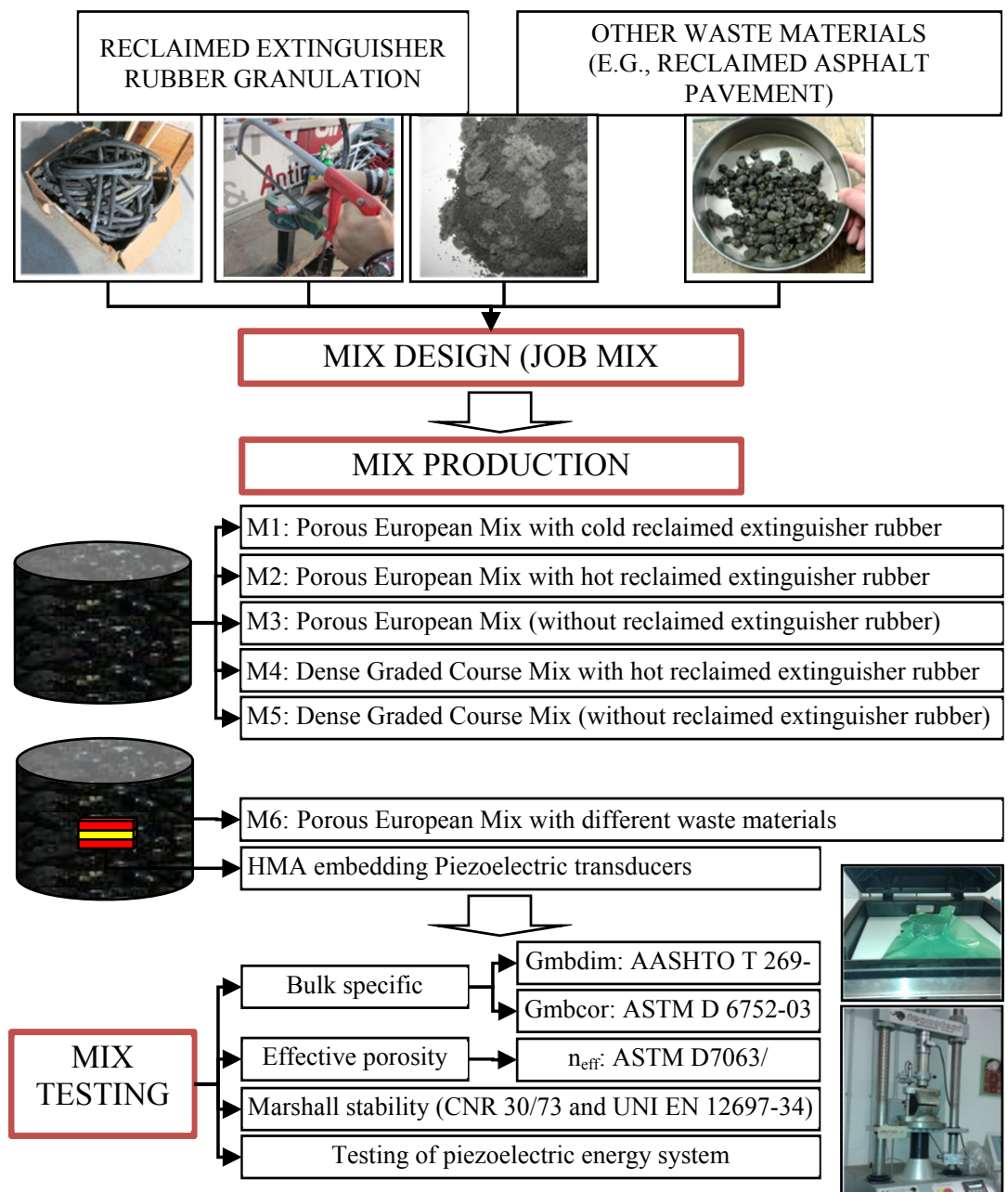

ON SITE TESTING

Figure 1: Design of experiments. 


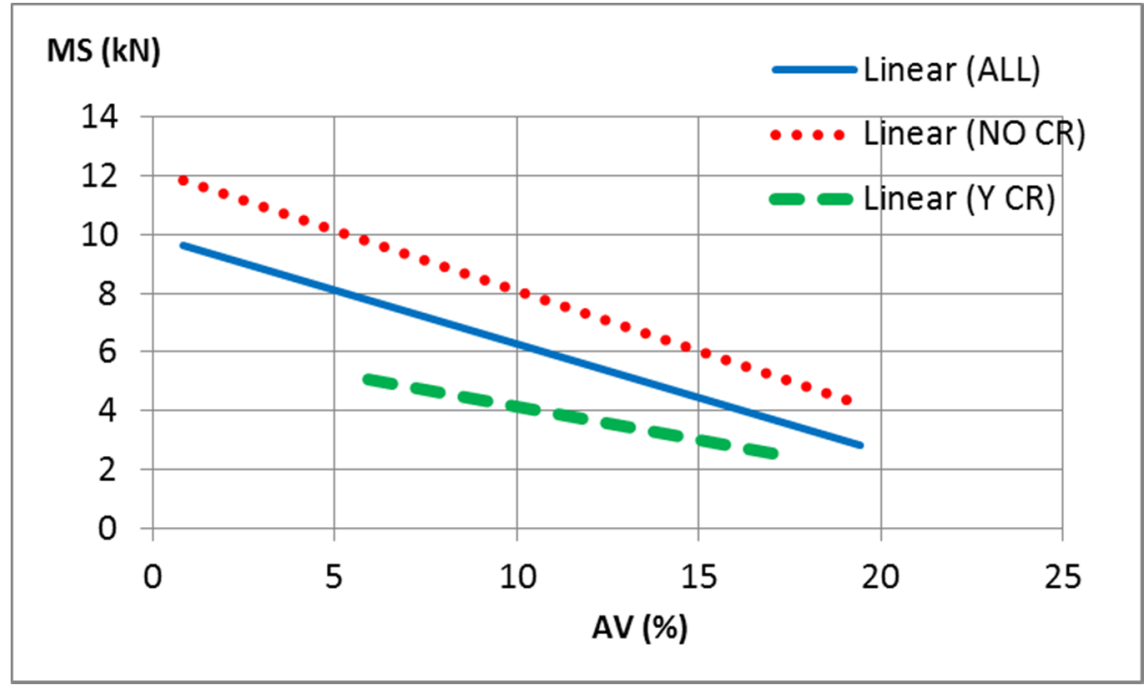

Figure 2: Marshall stability as a function of air voids content.

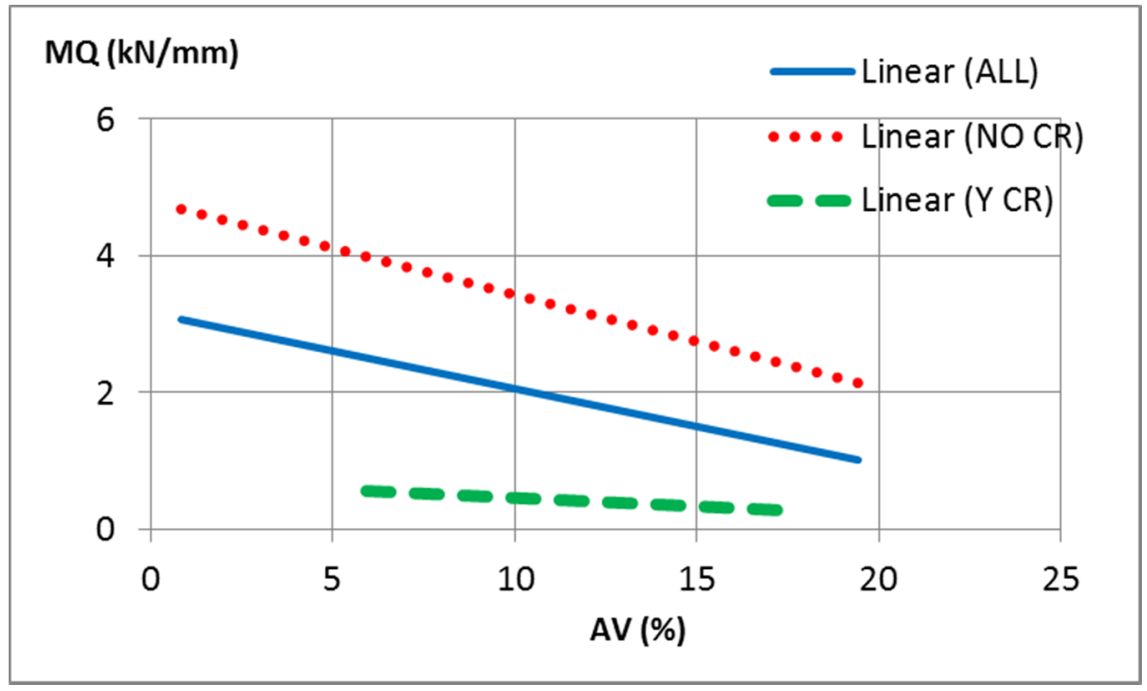

Figure 3: Marshall quotient as a function of air voids content. 


\section{Conclusions}

Although the dry process has a number of technical issues (including lack of standards, and uncertain performance), it has the potential to recycle more crumb rubber compared to the wet process and its mechanical properties (modulus, mechanical impedance) appear to have the potential for constructing innovative urban and rural infrastructures and for greening European freight terminals.

In light of the above, the goals of this study were the following: a) designing and testing innovative bituminous mixtures containing high percentages of crumb rubber (dry process); b) designing and testing innovative pavements in which the pressures caused by vehicles and/or motorcycles and/or pedestrians are converted into energy. Several mixes were designed and produced. Based on the results obtained, several options emerged as a possible solution for urban roads, rural roads, container terminals, and freight terminals. Aggregate gradation, bitumen (percentage and quality) and air voids content resulted as the possible keys to success in designing a CRM mixture. Higher bitumen content is supposed to be needed for the CRM mixtures compared to the conventional open-graded and dense-graded mixtures, for the same aggregate type.

Although studies are in progress, results are quite encouraging and can benefit both researchers and practitioners.

\section{Acknowledgements}

Paolo D'Agostino collaborated on the application as a student of the Master in Transportation Engineering, supplied in 2014-2015 at the Dipartimento di Ingegneria dell'Informazione, delle Infrastrutture e dell'Energia Sostenibile of the Università Mediterranea di Reggio Calabria.

\section{References}

[1] Hassan, N.O., Airey, G.D., Jayaa, R.P., Mashrosa, N., Aziza, M., A Review of Crumb Rubber Modification in Dry Mixed Rubberised Asphalt Mixtures, Jurnal Teknologi (Sciences \& Engineering) 70: 4, pp. 127-134, 2014.

[2] Celauro, B., Celauro, C., Lo Presti, D., Bevilacqua, A., Definition of a laboratory optimization protocol for road bitumen improved with recycled tire rubber, Construction and Building Materials, Volume 37, December 2012, pp. 562-572, 2012.

[3] Lo Presti, D., Recycled Tyre Rubber Modified Bitumens for road Asphalt Mixtures: A Literature Review. Constr. Build. Mater. 49: 863, 2013.

[4] Wright Asphalt Product Co. "The Rubber Modified Asphalt" http://www.asphaltroads.org/assets/_control/content/files/tire-rubbermodified-asphalt.pdf.

[5] Moreno F., Rubio M.C., Martinez-Echevarria M.J., Analysis of digestion time and the crumb rubber percentage in dry-process crumb rubber 
modified hot bituminous mixes. Construction and Building Materials, 28 December, 2010.

[6] Pereira S.M.S., Oliveira J.R.M., Freitas E.F., Machado P., Mechanical performance of asphalt mixture produced with cork or rubber granulates as aggregate partial substitutes. Construction and Building Materials, 8 January 2013.

[7] Thodesen, C., Shatanawi, K., Amirkhanian, S. Effect of Crumb Rubber Characteristics on Crumb Rubber Modified (CRM) Binder Viscosity. Constr. Build. Mater. 23: 295, 2009.

[8] Airey, G.D., Rahman, M. M., Collop, A. C., Absorption of Bitumen into Crumb Rubber Using the Basket Drainage Method. Int. J. Pavement. Eng. 4: 105, 2003.

[9] Rahman, M. M., Airey, G.D., Collop, A.C., The Mechanical Properties of the Dry Process CRM Asphalt Mixtures Following Short-term and Longterm Ageing. Retrieved in March 2015 from: http:/www.vegvesen.no/ attachment/110547/binary/192714? fast_title=Paper\%3A+The+Mechanical + Properties + of + the + Dry + Process + CRM + Asphalt + Mixtures + Following $+\mathrm{S}$ hort-term+and+Long-term+Ageing+, 2005.

[10] Lee, S.-J., Akisetty, C. K., Amirkhanian, S., The Effect of Crumb Rubber Modifier on the Performance Properties of Rubberized Binders in HMA pavements. Constr Build Mater. 22: 1368, 2008.

[11] FHWA, User Guidelines for Waste and Byproduct Materials in Pavement Construction, Publication Number: FHWA-RD-97-148. Retrieved in February, 2015 from: http://www.fhwa.dot.gov/publications/research/ infrastructure/structures/97148/st3.cfm

[12] Lopez-Moro F.J., Moro M.C., Hernandez-Olivares F., Witoszek-Schultz B., Alonso-Fernandez M., Microscopic analysis of the interaction between crumb rubber and bitumen in asphalt mixtures using the dry process, Construction and Building Materials 48(2013) 691-699.

[13] Feiteira-Dias J.L., Picado-Santos L.G., Capitao S.D., Mechanical performance of dry process fine crumb rubber asphalt mixtures placed on the Portuguese road network, Construction and Building Materials 73 pp. 247-254, 2014.

[14] Praticò F.G. \& Vaiana R., Improving infrastructure sustainability in suburban and urban areas: is Porous asphalt the right answer? And how?, Urban Transport: Urban Transport and the Environment in the 21st Century, Edited by: C. A. Brebbia, J. W. S. Longhurst, WIT Press, ISBN: 9781845645809, WIT Transactions on Ecology and the Environment, pp. 673-684, 2012.

[15] Praticò F.G., Vaiana R., A study on volumetric versus surface properties of wearing courses, Construction and Building Materials, 38, pp. 766775, Jan 2013, doi:10.1016/j.conbuildmat.2012.09.021, 2013.

[16] Maina, J., Steyn, W.J., van Wyk, E.B., Le Roux, F., Static and dynamic backcalculation analyses of an inverted pavement structure, Advanced Materials Research, 723, pp. 196-203, 2013. 
[17] Praticò, F.G., On the dependence of acoustic performance on pavement characteristics, Transportation Research Part D 29, pp. 79-87, 2014.

[18] Bosurgi, G., Perlongo, W., Numerical analysis of fatigue cracks growth in flexible pavements with the elastoplastic fracture mechanics method, Structure and Infrastructure Engineering, 10 (8), pp. 1027-1037, 2014.

[19] Agostinacchio, M., Ciampa, D., Olita, S., The vibrations induced by surface irregularities in road pavements - a Matlab ${ }^{\circledR}$ approach, European Transport Research Review, 6 (3), pp. 267-275, 2014.

[20] Russo F. \& Musolino G., A unifying modelling framework to simulate the Spatial Economic Transport Interaction process at urban and national scales. Journal of Transport Geography, 24, pp. 189-197, 2012.

[21] Russo, F., Musolino, G., Trecozzi, M.R., A system of models for the assessment of an urban distribution center in a city logistic plan, WIT Transactions on the Built Environment, Vol. 130, pp. 799-810, 2013.

[22] Lajnef et al. (2013), Report No. FHWA-HRT-12-072, Smart Pavement Monitoring System, May 2013.

[23] Yun et al., (2014) Smart wireless sensing and assessment for civil infrastructure, Structure and Infrastructure Engineering: Maintenance, Management, Life-Cycle Design and Performance, 10:4, 534-550.

[24] Ceylan et al., (2013), Highway Infrastructure Health Monitoring Using Microelectromechanical Sensors And Systems (Mems), Journal Of Civil Engineering And Management, Volume 19 (Supplement 1): S188-S201.

[25] Pearson, M., Eaton, M., Pullin, R., Featherston, C., Holford, K., Energy harvesting for aerospace structural health monitoring systems," Modern Practice in Stress and Vibration Analysis, Journal of Physics: Conference Series 382, 012025, 2012.

[26] Sunil S, Mallesh K.M., Chandrasekaraiah T., Experimental investigations on the performance of bituminous mixes with reclaimed asphalt pavement (RAP) materials (Case study Tumkur to Chitradurga-NH4). In: IJRET International Journal of Research in Engineering and Technology, Volume 03 Special Issue 06 May-2014, RRDCE, 2014. eISSN: 2319-1163, pISSN: 2321-7308.

[27] West R.C., Willis J.R., Case Studies on Successful Utilization of Reclaimed Asphalt Pavement and Recycled Asphalt Shingles in Asphalt Pavements. In: NCAT Report 14-06, 2014.

[28] Spurti O. Tambake, Dheeraj. N. Kumar, Manjunath. K. R., Laboratory investigation on hot mix asphalt using reclaimed asphalt pavement (RAP) for bituminous concrete mix. In: IJRET International Journal of Research in Engineering and Technology, Volume 03 Issue 06 June 2014. eISSN: 2319-1163, pISSN: 2321-7308.

[29] Hansen K. R., Copeland A., Annual Asphalt Pavement Industry Survey on Recycled Materials and Warm-Mix Asphalt Usage: 2009-2013. In: Final Report 2009-2013, National Asphalt Pavement Association, 2014.

[30] Neumann P. M., Kathirgamalingam Somasundaraswaran, Evaluation of strength characteristics of recycled asphalt pavement materials. In: 26th 
ARRB Conference - Research driving efficiency, Sydney, New South Wales, 2014.

[31] Hoppe E. J., Lane D. S., Fitch G. M., Shetty S., Feasibility of Reclaimed Asphalt Pavement (RAP) Use As Road Base and Subbase Material. In: Report No. VCTIR 15-R6, Virginia Center for Transportation Innovation and Research, 2015.

[32] Cannone Falchetto A., Ki Hoon Moon, Wistuba M. P., Microstructural Analysis and Rheological Modeling of Asphalt Mixtures Containing Recycled Asphalt Materials. In: Materials, 2014. ISSN 1996-1944

[33] Mhlongo S. M., Abiola O.S., Ndambuki J.M., Kupolati W.K., Use of Recycled Asphalt Materials for Sustainable Construction and Rehabilitation of Roads. In: International Conference on Biological, Civil and Environmental Engineering (BCEE-2014) March 17-18, 2014 Dubai (UAE), 2014.

[34] Zaumanisa M., Mallick R. B., Review of very high-content reclaimed asphalt use in plant-produced pavements: state of the art. In: International Journal of Pavement Engineering Volume 16, Issue 1, 2015.

[35] Cannone Falchetto A., Grönniger J., Wistuba M. P., Asphalt Pavement Recycling in Germany. In: ISAP APE 2015, 2015.

[36] Arulrajah A., Piratheepan J., Disfani M., Reclaimed Asphalt Pavement and Recycled Concrete Aggregate Blends in Pavement Subbases: Laboratory and Field Evaluation. In. Journal of Materials in Civil Engineering, Volume 26, Issue 2 (February 2014), Publisher: American Society of Civil Engineers, 2014. ISSN (print): 0899-1561 ISSN (online): 1943-5533.

[37] Stolle D.F.E., Peijun Guo, . Emery J.J, Mechanical properties of reclaimed asphalt pavement - natural aggregate blends for granular base. In: Canadian Journal of Civil Engineering, Volume 41, Number 6, June 2014, 2014.

[38] Jaafar Abubakar Sadeeq, Jibrin Mohammed Kaura, Ochepo Joshua, Ahmad Rabilu, Recycling of Reclaimed Asphalt Pavement (RAP) with Rice Husk Ash (RHA)/Ordinary Portland Cement (OPC) Blend As Filler. In: Jordan Journal of Civil Engineering, Volume 8, No. 4, 2014.

[39] Akinwumi I.I., Plasticity, Strength and Permeability of Reclaimed Asphalt Pavement and Lateritic Soil Blends. In: International Journal of Scientific \& Engineering Research, Volume 5, Issue 6, June-2014, 2014. ISSN 22295518.

[40] Tapsoba N., Sauzéat C., Di Benedetto H., Baaj H., Ech M., Behaviour of asphalt mixtures containing reclaimed asphalt pavement and asphalt shingle. In: Road Materials and Pavement Design, Volume 15, Issue 2, 2014.

[41] Taha R., Sirin O., Sadek H., Evaluation of Combined Excavation Waste and Reclaimed Asphalt Pavement Aggregates for Use in Road Bases and Sub-bases. In: J. Civil \& Environmental Engineering, Volume 4, Issue 2, 2014. ISSN: 2165-784X JCEE.

[42] Praticò, F.G., Amodeo, L., Lamari, D., Lanciano, C., Placido, V., Praticò, M., Pavement LCCA for city logistics, In WIT Transactions on the Built 
Environment, volume 146, 2015. ISSN: 1746-4498, Digital ISSN: 17433509.

[43] Amodeo L., Lamari D., Musolino G., Placido V., Polimeni A., Praticò M. \& A. Vitetta, An ex-ante evaluation of last-mile freight distribution services for city logistics In WIT Transactions on the Built Environment, volume 146, 2015. ISSN: 1746-4498, Digital ISSN: 1743-3509.

[44] Russo F., Rindone C., D’Agostino P., Lanciano C. \& Scattarreggia T., Long distance freight transport to the provisioning of a city logistics. In WIT Transactions on the Built Environment, volume 146, 2015. ISSN: 1746-4498, Digital ISSN: 1743-3509.

[45] Gattuso D., Cassone G.C., Lanciano C., Placido V. \& M. Praticò. A freight urban distribution center design with micro-simulation support for city logistics. In WIT Transactions on the Built Environment, volume 146, 2015. ISSN: 1746-4498, Digital ISSN: 1743-3509.

[46] Panuccio P, Amodeo L., D’Agostino P., Lamari D. \& T. Scattarreggia. Urban regeneration and smart city according EU strategies: urban distribution center in city logistics. In WIT Transactions on the Built Environment, volume 146, 2015. ISSN: 1746-4498, Digital ISSN: 17433509.

[47] Kandhal, P.S., Foo, K.Y., Mallick, R.B., A Critical Review of VMA Requirements In Superpave. NCAT Report No. 98-1, 1998.

[48] Hmoud, H.R., Evaluation of VMA and Film Thickness Requirements in Hot-Mix Asphalt, Modern Applied Science Vol. 5, No. 4, 2011. doi:10.5539/mas.v5n4p166. 166 ISSN 1913-1844 E-ISSN 1913-1852. www.ccsenet.org/mas. Retrieved in March, 2015 from: http://ccsenet.org/journal/index.php/mas/article/viewFile/11635/8279, 2011.

[49] Praticò, F. G., and Moro, A., In-lab and on-site measurements of hot mix asphalt density: Convergence and divergence hypotheses, Constr. Build. Mater., 25(2), 1065-1071, 2011.

[50] Tao Ma, Hao Wang, Yongli Zhao, Xiaoming Huang, Laboratory Investigation on Residual Strength of Reclaimed Asphalt Mixture for Cold Mix Recycling. In: International Journal of Pavement Research and Technology, Vol.8 No.1 Jan. 2015. 